Supporting Information for

\title{
Evaporative Crystallization of Spirals
}

Samantha A. McBride, Susmita Dash, Sami Khan, Kripa K. Varanasi

22 pages

\section{Contents}

$\begin{array}{lc}\text { Analysis of Forces } & \text { S4 }\end{array}$

$\begin{array}{ll}\text { Timescales } & \text { S5 }\end{array}$

$\begin{array}{ll}\text { Nanoparticle Experiments } & \text { S9 }\end{array}$

$\begin{array}{ll}\text { Other Salts } & \text { S9 }\end{array}$

$\begin{array}{lr}\text { Fermat's Spiral } & \text { S12 }\end{array}$

$\begin{array}{lr}\text { Spiral vs. Concentric Rings } & \text { S15 }\end{array}$

$\begin{array}{ll}\text { Surface Charecterization } & \text { S16 }\end{array}$

Coating Height

Surface Roughness

XPS Spectra

$\begin{array}{ll}\text { Repeatability } & \text { S19 }\end{array}$

$\begin{array}{lr}\text { Derivation of Equation } 3 & \text { S20 }\end{array}$

$\begin{array}{ll}\text { Additional References } & \text { S22 }\end{array}$ 


\section{Figures}

Figure S1. Sketch defining different experimental timescales.

Figure S2. Timescale of drop rupture (Table S3) plotted against predicted values from equation S4. Colored circles correspond to different temperatures (red $=85^{\circ} \mathrm{C}$, orange $=75^{\circ} \mathrm{C}$, yellow $=$ $70{ }^{\circ} \mathrm{C}$, green $=65^{\circ} \mathrm{C}$, light blue $=60^{\circ} \mathrm{C}$, dark blue $=55^{\circ} \mathrm{C}$, purple $=45^{\circ} \mathrm{C}$ ). Line indicates a $1: 1$ ratio of experimental data to predicted values.

Figure S3. Time series showing evaporation of a $5 \mu \mathrm{L}$ drop containing $0.1 \%$ latex nanospheres. Width of each image is $3 \mathrm{~mm}$.

Figure S4. Deposits left on the substrates by different salt solutions on a substrate $\left(\theta_{\mathrm{A}}=98^{\circ}\right.$, $\theta_{\mathrm{R}}=30^{\circ}$ ) heated to $70^{\circ} \mathrm{C}$. (a) calcium carbonate, (b) sodium carbonate, (c) calcium sulfate, (d) calcium iodate, (e) sodium chloride (at 10\% of saturation concentration), and (f) silver sulfate.

Figure S5. Depsosits from different concentrations of sodium chloride on a substrate $\left(\theta_{\mathrm{A}}=98^{\circ}\right.$, $\left.\theta_{\mathrm{R}}=30^{\circ}\right)$ heated to $70^{\circ} \mathrm{C}$. (a) $1 \%$ of saturation $(3.6 \mathrm{~g} / \mathrm{L})$, (b) $2 \%$ of saturation concentration, (c) $5 \%$ of saturation concentration, (d) $10 \%$ of saturation concentration.

Figure S6. Optical microscope images with overlaid Fermat's spiral to measure parameter "a".

Figure S7. (a) The radial position, $n$, as a function of normalized time $\left(t^{*}=t / t_{2}\right.$, where $t_{2}$ is the burst time defined in Figure S1) (b) Fermat's equation overlaid on SEM image (same as main text Figure 5a). (c) Time series demonstrating the movement of the pinning and depinning points for the given sample.

Figure S8. Plot of normalized equations S9 and S16, showing the general shape of the radial position of the contact line with time.

Figure S9. Some examples of samples that failed to form clean patterns. Scale bar is $0.5 \mathrm{~mm}$. (a) spirals failed to form due to crystals not pinning the contact line uniformly (b) drop ruptured on the upper left instead of at center (c) spirals failed to form due to roughness of the surface (d) calcium sulfate needles formed in the bulk deposit on the surface prior to rupture and disrupt spiral propagation. (e) Microscopic spiral has formed around a calcium sulfate crystal that formed in the bulk and deposited on the surface. 


\section{Tables}

Table S1. Advancing angle $\theta_{A}$, equilibrium angle $\theta_{E}$, receding angle $\theta_{R}$, contact angle hysteresis, pinning force $F_{P}$, and potential energy barrier $U$ for surfaces used.

Table S2. Total evaporation times ( $t_{1}$, minutes) for complete desiccation from start to finish.

Table S3. Dry-out times ( $t_{2}$, seconds), the time between initial rupture and complete desiccation.

Table S4. Rupture time ( $t_{3}$, seconds), defined as the time between initial rupture and re-pinning of the contact line. Sensitivity was $1 / 24$ s (0.042s).

Table S5. Pinning time ( $t_{4}$, seconds), defined as the time the interior contact line pinning at a given point, and then depinning from that same point

Table S6. Values of density, water vapor in air, diffusion of water vapor in air, evaporation rate, and diffusion rate of calcium ions in solution as a function of temperature.

Table S7. Percent of pattern-forming samples that form spirals. 


\section{Analysis of Forces}

The stick-slip behavior of evaporating drops has been previously correlated to energy barriers preventing recession of the interface. The pinning force of a drop to a substrate is a function of both the advancing $\left(\theta_{A}\right)$ and receding $\left(\theta_{R}\right)$ angles of the surface:

$$
F_{P}=\gamma\left(\cos \theta_{R}-\cos \theta_{A}\right)
$$

Where $\gamma$ is the surface tension of water, $73 \mathrm{mN} / \mathrm{m}$ at $25^{\circ} \mathrm{C}\left(66 \mathrm{mN} / \mathrm{m}\right.$ at $\left.60^{\circ} \mathrm{C}\right)$. The energy barrier resisting interface movement is: ${ }^{1}$

$$
\Delta G=\gamma \pi R^{2}\left(\frac{2}{1+\cos \theta}-\cos \theta_{e}\right)
$$

Where $R$ is the radius of the drop, $\theta_{e}$ is the equilibrium (Young) contact angle, and $\theta$ is the instantaneous contact angle (which varies between $\theta_{e}$ and $\theta_{R}$ for a pinned contact line). The excess free energy increases when the triple line is pinned as the deviation of the contact angle from the equilibrium angle increases. When the excess energy exceeds the potential energy barrier for depinning, the drop may depin and recede until it is able to repin. Therefore, the potential energy barrier for depinning is approximately:

$$
U=\gamma \pi R^{2}\left(\frac{2}{1+\cos \theta_{R}}-\cos \theta_{e}\right)
$$

Where we approximate that the contact angle after a slip is similar to the equilibrium contact angle and that depinning occurs at the receding angle. In reality, the new contact angle of a droplet that has repined after a "slip" will likely be below the equilibrium contact angle. The advancing, receding, and equilibrium angles for each of the surfaces used in the present investigation were measured using DI water and are reported in Table S1, along with estimates for the pinning force (Eqn. S1) and the potential energy barrier (Eqn. S3). Contact angles for DI water remain valid for the saturated calcium sulfate solution, as the deviation in surface tension due to the presence of the salt is negligible. ${ }^{2}$ However, (as discussed in the main text) the receding angle of the bursting drop will deviate from the DI water value due to crystallization.

Table S1. Advancing angle $\theta_{A}$, equilibrium angle $\theta_{E}$, receding angle $\theta_{R}$, contact angle hysteresis, pinning force $F_{P}$, and potential energy barrier $U$ for surfaces used.

\begin{tabular}{|l|c|c|c|c|c|c|c|c|}
\hline Surface & Color & $\boldsymbol{R}(\mathbf{m m})$ & $\boldsymbol{\theta}_{\boldsymbol{A}}$ & $\boldsymbol{\theta}_{\boldsymbol{E}}$ & $\boldsymbol{\theta}_{\boldsymbol{R}}$ & $\boldsymbol{\theta}_{\boldsymbol{A}}-\boldsymbol{\theta}_{\boldsymbol{R}}$ & $\boldsymbol{F}_{\boldsymbol{P}}(\mathbf{m N} / \mathbf{m})$ & $\boldsymbol{U}(\boldsymbol{\mu J})$ \\
\hline Ceria12 & Purple & 1.35 & $75^{\circ}$ & $73^{\circ}$ & $12^{\circ}$ & $63^{\circ}$ & 52.5 & 0.31 \\
\hline Ceria18 & light purple & 1.30 & $98^{\circ}$ & $93^{\circ}$ & $18^{\circ}$ & $80^{\circ}$ & 79.6 & 0.45 \\
\hline Ceria22 & Green & 1.31 & $96^{\circ}$ & $95^{\circ}$ & $22^{\circ}$ & $74^{\circ}$ & 75.3 & 0.45 \\
\hline Erbia27 & Green & 1.31 & $95^{\circ}$ & $94^{\circ}$ & $27^{\circ}$ & $68^{\circ}$ & 71.4 & 0.45 \\
\hline Ceria35 & Purple/Pink & 1.34 & $89^{\circ}$ & $80^{\circ}$ & $35^{\circ}$ & $54^{\circ}$ & 58.5 & 0.44 \\
\hline Ceria42 & Blue & 1.23 & $107^{\circ}$ & $105^{\circ}$ & $42^{\circ}$ & $55^{\circ}$ & 70.9 & 0.46 \\
\hline
\end{tabular}




\section{Timescales}

There are a number of time scales occurring throughout these processes (see Figure S1). The first is the overall time between deposition of the $5 \mu \mathrm{L}$ drop and complete evaporation $\left(t_{l}\right)$, shown in Table S2. The second is the "rupture" time, $t_{2}$, defined here as the time between the rupture of the interface and complete desiccation (Table S3). The "bursting time," $t_{3}$, of Table S4 is the time between drop rupture and the first instance of contact line pinning. This timescale shows a strong dependence on the surface and less dependence on the substrate temperature due to its inertial origins. The fourth experimental timescale shown here is the pinning timescale, $t_{4}$ (Table S5), defined as the time starting at the point a given section of the contact line pins and ending when that same segment of the contact line depins from the formed crystalline needles.

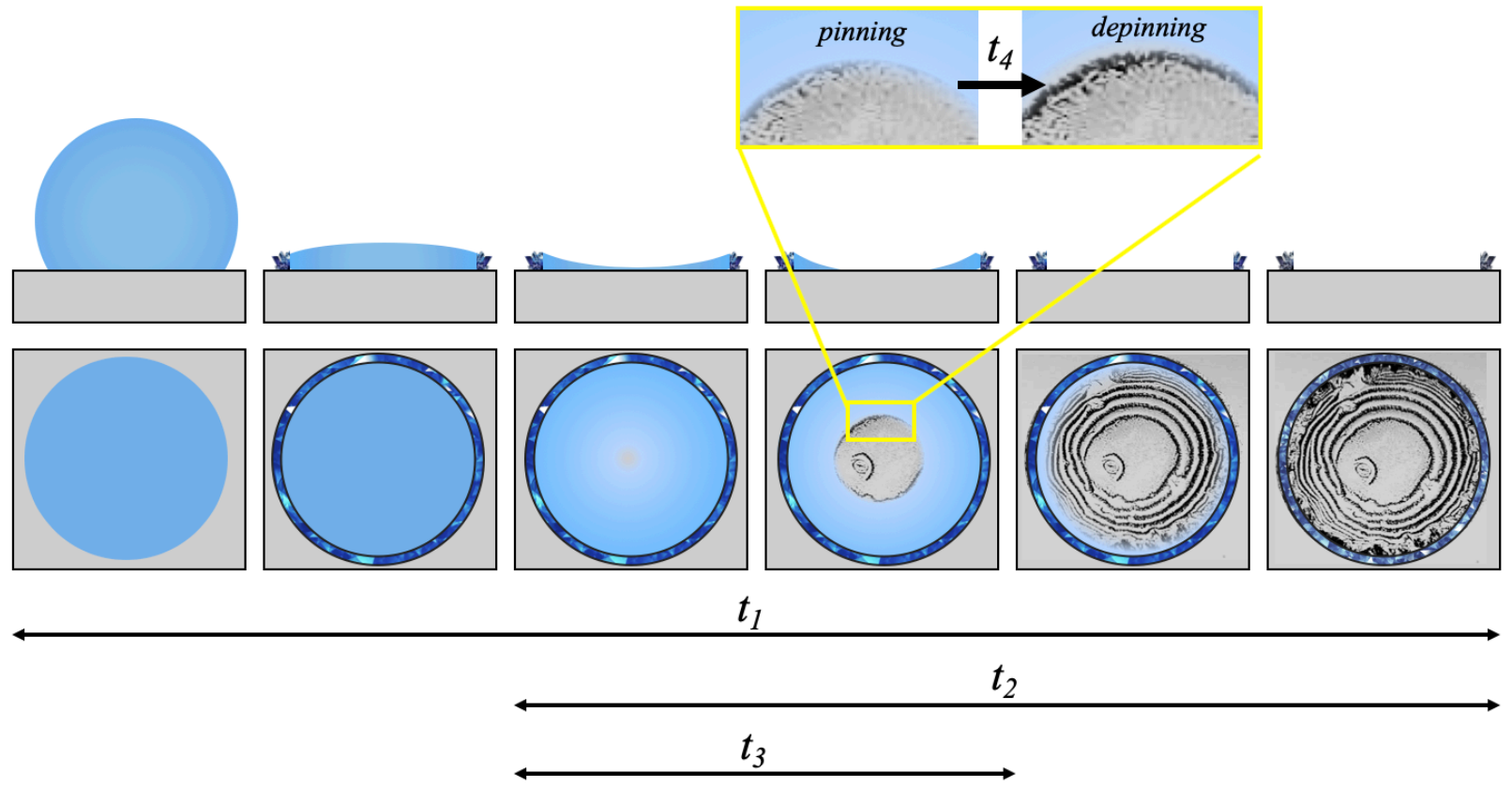

Figure S1. Defining different experimental timescales.

Table S2. Total evaporation times ( $t_{1}$, minutes) for complete desiccation from start to finish.

\begin{tabular}{|c|c|c|c|c|c|c|c|}
\hline Surface & $\mathbf{4 5}^{\circ} \mathbf{C}$ & $\mathbf{5 5}^{\circ} \mathbf{C}$ & $\mathbf{6 0}^{\circ} \mathbf{C}$ & $\mathbf{6 5}^{\circ} \mathbf{C}$ & $\mathbf{7 0}^{\circ} \mathbf{C}$ & $\mathbf{7 5}^{\circ} \mathbf{C}$ & $\mathbf{8 5}^{\circ} \mathbf{C}$ \\
\hline Ceria12 & 5.7 & 4.5 & 2.7 & 2.3 & 1.9 & 1.3 & 0.97 \\
\hline Ceria18 & 6.2 & 3.9 & 2.7 & 1.9 & 1.3 & 0.98 & 0.88 \\
\hline Ceria22 & 6.6 & 4.1 & 2.5 & 2.1 & 1.6 & 1.4 & 0.73 \\
\hline Erbia27 & 6.0 & 3.4 & 2.0 & 1.6 & 1.2 & 0.76 & 0.63 \\
\hline Ceria35 & 6.0 & 3.6 & 2.6 & 2.0 & 1.6 & 1.2 & 0.87 \\
\hline Ceria42 & 6.5 & 3.9 & 2.4 & 2.0 & 1.7 & 1.3 & 0.72 \\
\hline
\end{tabular}


Table S3. Rupture time ( $t_{2}$, seconds), the time between initial rupture and complete desiccation.

\begin{tabular}{|c|c|c|c|c|c|c|c|}
\hline Surface & $\mathbf{4 5}^{\circ} \mathbf{C}$ & $\mathbf{5 5}^{\circ} \mathbf{C}$ & $\mathbf{6 0}^{\circ} \mathbf{C}$ & $\mathbf{6 5}^{\circ} \mathbf{C}$ & $\mathbf{7 0}^{\circ} \mathbf{C}$ & $\mathbf{7 5}^{\circ} \mathbf{C}$ & $\mathbf{8 5}^{\circ} \mathbf{C}$ \\
\hline Ceria12 & 11 & 7 & 6 & 6 & 4 & 3.4 & 3 \\
\hline Ceria18 & 15 & 12 & 7.5 & 6 & 2.5 & 2 & 1.3 \\
\hline Ceria22 & 17 & 12 & 6.5 & 8 & 4 & 2.5 & 1.4 \\
\hline Erbia27 & 13 & 10 & 6 & 3.5 & 4 & 2.6 & 1 \\
\hline Erbia35 & 17 & 11 & 8 & 6 & 4.5 & 3.25 & 1.5 \\
\hline Ceria42 & 8 & 10 & 5 & 5 & 4 & 2 & 1.8 \\
\hline
\end{tabular}

Table S4. Burst time ( $t_{3}$, seconds), defined as the time between initial rupture and re-pinning of the contact line. Sensitivity was $1 / 24 \mathrm{~s}(0.042 \mathrm{~s})$.

\begin{tabular}{|c|c|c|c|c|c|c|c|}
\hline Surface & $\mathbf{4 5}^{\circ} \mathbf{C}$ & $\mathbf{5 5}^{\circ} \mathbf{C}$ & $\mathbf{6 0}^{\circ} \mathbf{C}$ & $\mathbf{6 5}^{\circ} \mathbf{C}$ & $\mathbf{7 0}^{\circ} \mathbf{C}$ & $\mathbf{7 5}^{\circ} \mathbf{C}$ & $\mathbf{8 5}^{\circ} \mathbf{C}$ \\
\hline Ceria12 & 1.13 & 0.79 & 0.83 & 0.46 & 0.79 & 0.63 & 1 \\
\hline Ceria18 & 0.63 & 0.21 & 0.25 & 0.58 & 0.42 & 0.46 & 0.58 \\
\hline Ceria22 & 0.29 & 0.21 & 0.17 & 0.17 & 0.33 & 0.66 & 1.25 \\
\hline Erbia27 & 0.25 & 0.21 & 0.29 & 0.17 & 0.25 & 0.25 & 0.66 \\
\hline Erbia35 & 0.24 & 0.25 & 0.17 & 0.17 & 0.17 & 0.21 & 0.73 \\
\hline Ceria42 & 0.24 & 0.25 & 0.21 & 0.25 & 0.21 & 0.29 & 0.83 \\
\hline
\end{tabular}

Table S5. Pinning time ( $t_{4}$, seconds), defined as the time the interior contact line pinning at a given point, and then depinning from that same point

\begin{tabular}{|c|c|c|c|c|c|c|c|}
\hline Surface & $\mathbf{4 5}^{\circ} \mathbf{C}$ & $\mathbf{5 5}^{\circ} \mathbf{C}$ & $\mathbf{6 0}^{\circ} \mathbf{C}$ & $\mathbf{6 5}^{\circ} \mathbf{C}$ & $\mathbf{7 0}^{\circ} \mathbf{C}$ & $\mathbf{7 5}^{\circ} \mathbf{C}$ & $\mathbf{8 5}^{\circ} \mathbf{C}$ \\
\hline Ceria12 & 1.3 & 1.0 & 0.9 & 0.6 & 0.6 & 0.6 & 0.6 \\
\hline Ceria18 & 2.7 & 2.4 & 2 & 0.5 & 0.4 & 0.5 & 0.4 \\
\hline Ceria22 & 4.0 & 2.6 & 2.9 & 2.0 & 1.3 & 0.9 & 0.3 \\
\hline Erbia27 & 5.2 & 3.0 & 2.2 & 1.5 & 1.1 & 1.2 & 0.6 \\
\hline Erbia35 & 4.4 & 2.0 & 2.1 & 1.5 & 1.5 & 0.8 & 0.7 \\
\hline Ceria42 & 3.0 & 2.3 & 2.1 & 2.3 & 1.6 & 0.4 & 0.4 \\
\hline
\end{tabular}

For estimation of the diffusive and evaporative timescales presented in the main text, the diffusion rate of calcium ions in solution as a function of temperature, and the evaporative flux $\left(J_{o}=D_{v a p}\left(C_{T}-C_{o o}\right) / \rho\right)$ as a function of temperature were calculated, as shown in Table S6.

Table S6. Values of density, water vapor in air, diffusion of water vapor in air, evaporation rate, and diffusion rate of calcium ions in solution as a function of temperature.

\begin{tabular}{|l|c|c|c|c|c|c|c|c|}
\hline Temp. & $\mathbf{4 5}^{\circ} \mathbf{C}$ & $\mathbf{5 5}^{\circ} \mathbf{C}$ & $\mathbf{6 0}^{\circ} \mathbf{C}$ & $\mathbf{6 5}^{\circ} \mathbf{C}$ & $\mathbf{7 0}^{\circ} \mathbf{C}$ & $\mathbf{7 5}^{\circ} \mathbf{C}$ & $\mathbf{8 5}^{\circ} \mathbf{C}$ & $\mathbf{9 5}^{\circ} \mathbf{C}$ \\
\hline $\boldsymbol{\rho}\left(\mathrm{kg} / \mathrm{m}^{3}\right)$ & 990 & 986 & 983 & 980 & 978 & 975 & 969 & 962 \\
\hline $\boldsymbol{C}_{\boldsymbol{T}}\left(\mathrm{kg} / \mathrm{m}^{3}\right)$ & 0.061 & 0.107 & 0.130 & 0.165 & 0.200 & 0.245 & 0.355 & 0.505 \\
\hline $\boldsymbol{D}_{\text {vap }}\left(\mathrm{m}^{2} / \mathrm{s}\right)$ & $2.84 * 10^{-5}$ & $2.99 * 10^{-5}$ & $3.07 * 10^{-5}$ & $3.14^{*} 10^{-5}$ & $3.22^{*} 10^{-5}$ & $3.30^{*} 10^{-5}$ & $3.47^{*} 10^{-5}$ & $3.63^{*} 10^{-5}$ \\
\hline $\boldsymbol{J}_{\boldsymbol{o}}\left(\mathrm{m}^{2} / \mathrm{s}\right)$ & $1.3^{*} 10^{-9}$ & $2.7 * 10^{-9}$ & $3.5^{*} 10^{-9}$ & $4.7 * 10^{-9}$ & $6.0 * 10^{-9}$ & $7.7 * 10^{-9}$ & $1.2^{*} 10^{-8}$ & $1.8^{*} 10^{-8}$ \\
\hline $\boldsymbol{D}_{\boldsymbol{C a}}{ }^{2+}\left(\mathrm{m}^{2} / \mathrm{s}\right)$ & $1.27^{*} 10^{-9}$ & $1.55^{*} 10^{-9}$ & $1.71 * 10^{-9}$ & $1.86^{*} 10^{-9}$ & $2.03 * 10^{-9}$ & $2.20^{*} 10^{-9}$ & $2.56^{*} 10^{-9}$ & $2.99^{*} 10^{-9}$ \\
\hline
\end{tabular}


A previous investigation exploring the influence of temperature on the ring formation of graphene oxide particles demonstrated that different patterns could be explained as a balance between the evaporation rate and the timescale for deposition of the colloid. ${ }^{3}$ Following this logic, we sought to model the evaporative time scale (aka, the time given in Table S3) to explain pattern forming behavior. A mass balance across the liquid vapor interface is:

$$
\begin{gathered}
\frac{d V}{d t}=\int_{R(t)}^{R_{o}} \frac{\partial h}{\partial t} 2 \pi r d r=-2 \pi\left(R_{o}-R(t)\right) J_{o} \\
J_{o}=\frac{D\left(C_{L V}-C_{\infty}\right)}{\rho_{L}}
\end{gathered}
$$

Where $J_{o}$ is the evaporative flux, $D$ is the diffusion of water vapor in air, $C_{L V}$ is the saturation concentration of water vapor at the heated air/water interface, and $C_{\infty}$ is the equilibrium concentration of water vapor in the bulk.

The height profile of the drop during rupture is subject to three boundary conditions: (1) The height is equal to the height of the crystal ring at the outer radius $\left(h\left(r=R_{o}\right)=h_{c}\right)$, (2) the height is zero at the receding contact line $(h(r=R(t))=0)$, and (3) the curvature of the profile at the contact line is given by $d h / d r(r=R(t))=\tan \theta_{R}$. We assume a quadratic self-similar profile for the depth based on previous experimental ${ }^{4}$ and theoretical ${ }^{5}$ investigations as well as observations of the present system. Solving a quadratic equation for the given boundary conditions, we estimate the depth profile as:

$$
h(r)=\left[\frac{h_{c}-\left(R_{o}-R(t)\right) \tan \theta_{R}}{\left(R_{o}-R(t)\right)^{2}}\right](r-R(t))^{2}+\tan \theta_{R}(r-R(t))
$$

If we then neglect all terms containing the factor $\tan \theta_{R}$ due to the very low receding angle, we arrive at a simplified version of the height profile as:

$$
h(r)=\frac{h_{c}(r-R(t))^{2}}{\left(R_{\max }-R(t)\right)^{2}}
$$

Plugging equation S6 into the mass balance of equation S4 and solving gives a differential equation of the form:

$$
\left[\frac{1}{12}\left(-R_{o}^{4}+R(t)^{4}\right)+\frac{1}{6}\left(-R_{o} R(t)^{3}+R_{o}^{3} R(t)\right)\right] \frac{d R}{d t}=\left(R_{o}-R(t)\right)^{4} \frac{j_{o}}{2 h_{c}} \quad \text { Eqn. S7 }
$$

Which can be simplified and rearranged as:

$$
\left[\frac{R_{o}+R(t)}{R_{o}-R(t)}\right] \frac{d R}{d t}=-\frac{6 J_{o}}{h_{c}}
$$


This differential equation is then solved to find an expression for the retracting inner radius as a function of time:

$$
R(t)=R_{o}\left(1+2 W\left(\frac{-1}{2 R_{o}} \exp \left(\frac{-3 j_{o}}{h_{c} R_{O}} t-\frac{1}{2}\right)\right)\right)
$$

Where $\mathrm{W}$ is the product log function, sometimes called the Lambert $\mathrm{W}$-function. This somewhat complicated expression for the retracting front with time allows for the extraction of a simple timescale describing bursting of the drop (i.e., timescale $t_{2}$ )

$$
t_{\text {model }}=\frac{1}{3 \pi} \frac{h_{c} R_{\max }}{j_{o}}
$$

Plotting this evaporation timescale against experimental data for the burst time of Table S3 (where the evaporation time $t_{2}$ is defined as the time between drop rupture and complete desiccation) yields Figure S2. This model for the evaporative timescale works well for most of the data, but breaks down at the lowest temperature of $45^{\circ} \mathrm{C}$; likely due to a decreased dependence of the phenomena on heat transfer alone.

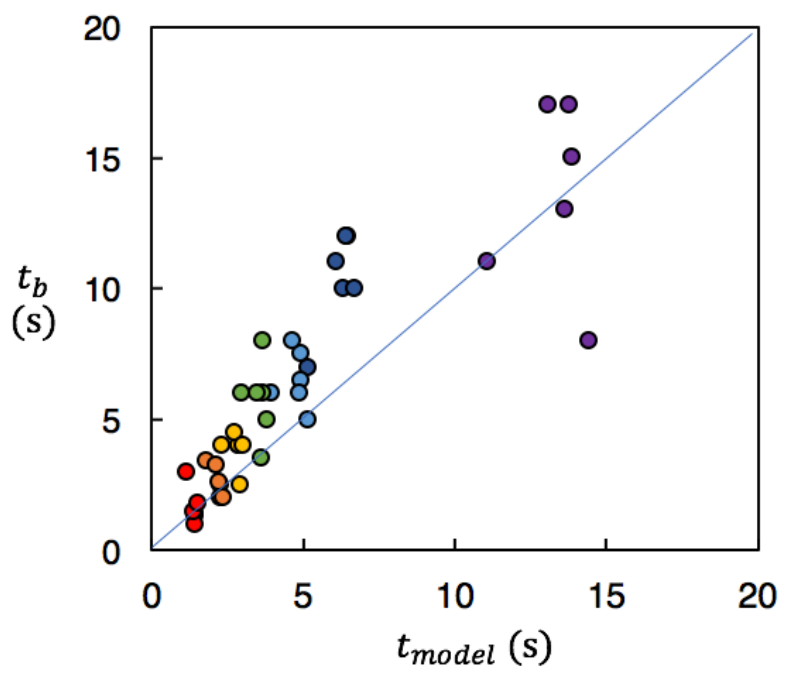

Figure S2. Timescale of drop rupture (Table S3) plotted against predicted values from equation S7. Colored circles correspond to different temperatures $\left(\right.$ red $=85^{\circ} \mathrm{C}$, orange $=75^{\circ} \mathrm{C}$, yellow $=$ $70{ }^{\circ} \mathrm{C}$, green $=65^{\circ} \mathrm{C}$, light blue $=60^{\circ} \mathrm{C}$, dark blue $=55^{\circ} \mathrm{C}$, purple $=45^{\circ} \mathrm{C}$ ). Line indicates a $1: 1$ ratio of experimental data to predicted values. 


\section{Nanoparticle Controls}

Control experiments using $0.1 \%$ latex nanospheres suspension in water were conducted on the surface with $\theta_{A}=98^{\circ}, \theta_{R}=18^{\circ}$ at $70^{\circ} \mathrm{C}$ (Figure S3). The evaporation proceeds similarly to the experiments using dissolved calcium sulfate solution. A thin ring of particles deposit at the outer contact ring, which then pins the contact line. The drop evaporates into a thin film which eventually ruptures. The rupturing film entrains the particles, dragging them with the fluid instead of depositing on the substrate. Unlike the crystallizing solution, this film ruptures somewhat randomly and does not retract towards the outer ring. This is because the particles do not form the three-dimensional outer ring. Thus, the spiral and concentric ring patterns are unique to the crystallizing solution in this system.

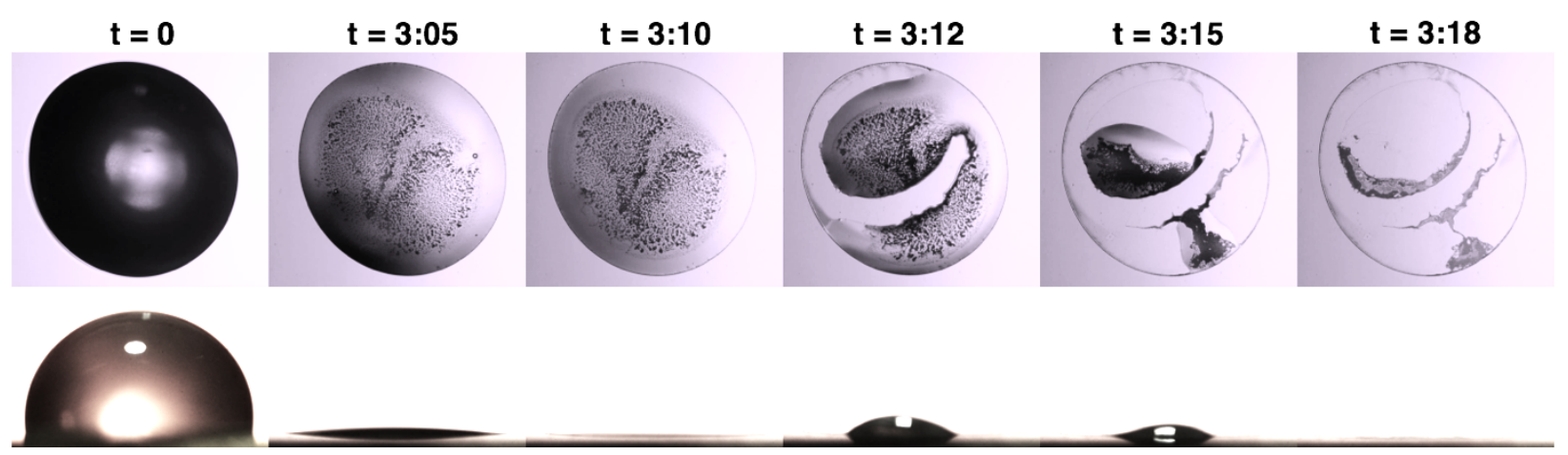

Figure S3. Time series showing evaporation of a drop containing $0.1 \%$ latex nanospheres. Width of each image is $3 \mathrm{~mm}$.

\section{Other Salts}

In addition to calcium sulfate, other salts were tested to probe the repeatability of spiral formation across different systems, as shown in Figure S4. All of these $5 \mu \mathrm{L}$ samples were deposited on the same substrate $\left(\theta_{A}=98^{\circ}, \theta_{R}=30^{\circ}\right)$ heated to $70^{\circ} \mathrm{C}$, and calcium sulfate was included as a control for direct comparision (S4c). 

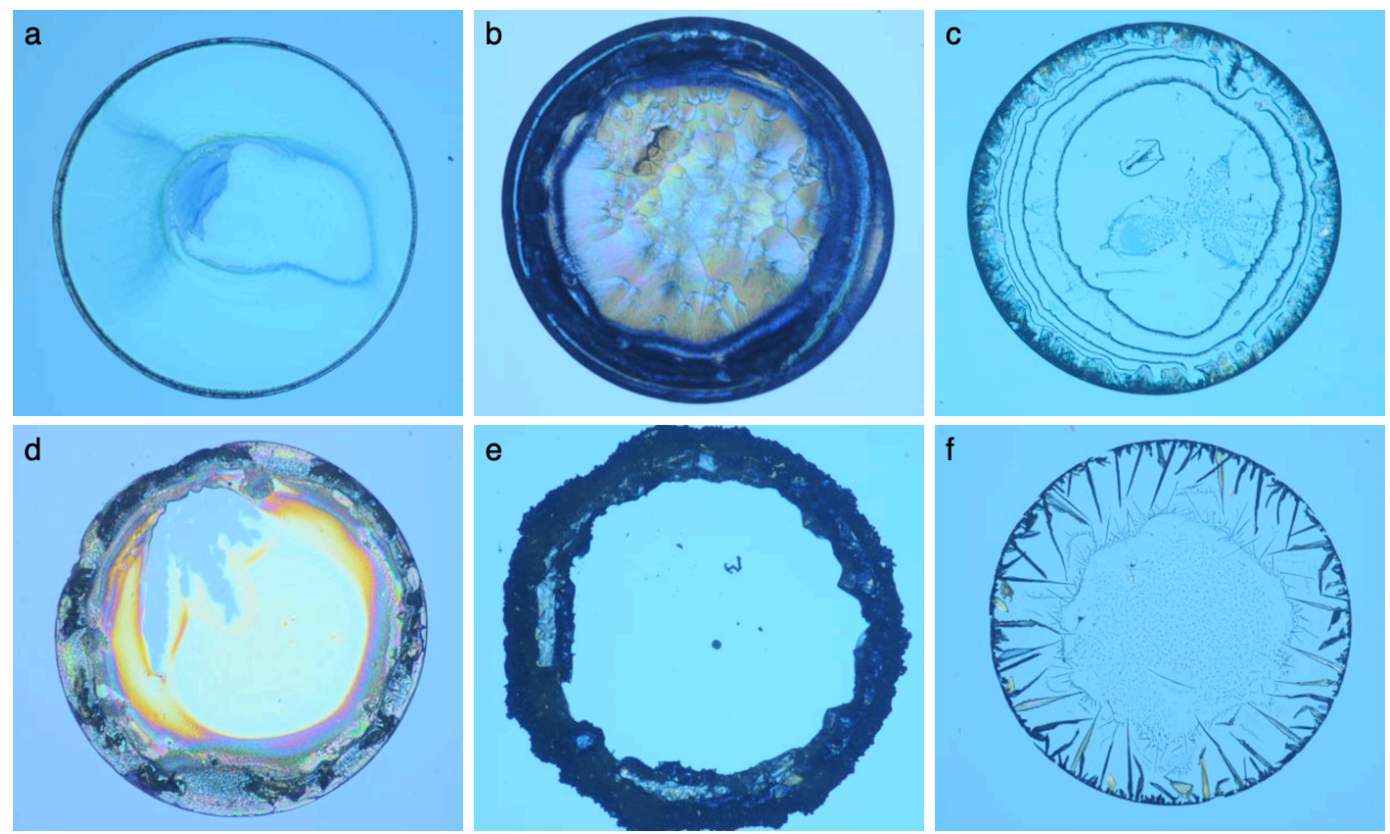

Figure S4. Deposits left on the substrates by different salt solutions on a substrate $\left(\theta_{\mathrm{A}}=98^{\circ}\right.$, $\theta_{\mathrm{R}}=30^{\circ}$ ) heated to $70^{\circ} \mathrm{C}$. (a) calcium carbonate, (b) sodium carbonate, (c) calcium sulfate, (d) calcium iodate, (e) sodium chloride (at $10 \%$ of saturation concentration), and (f) silver sulfate.

As explained in the text and shown in equation 7, the two parameters important for patterning are (1) the system geometry, and (2) the ratio of evaporation to diffusion. In particular, the ratio between the relative height and radial dimension of the evaporating drop profile strongly control the ratio between the evaporative and crystallization timescales. The other salts shown here fail to form patterns primarly due to geometrical reasons. Calcium carbonate (S4a) has a solubility $\sim 100 \mathrm{x}$ smaller than that of calcium sulfate $(0.015 \mathrm{vs} .2 .1 \mathrm{~g} / \mathrm{L})$, and there is insufficient mass to allow for formation of an outer ring. Thus, the geometry of the evaporating wedge is altered. Sodium carbonate (S4b) and calcium iodate (S4d) have sufficient solubilities $\left(2.4 \mathrm{~g} / \mathrm{L}\right.$ and $200 \mathrm{~g} / \mathrm{L}$ at $20^{\circ} \mathrm{C}$, respectively); however, the kinetics of crystal growth are slower; meaning that the resulting precipitate at the outer edge does not form the well-shaped crystalline "bowl" modeling the shape of the drop that calcium sulfate does. Thus, the width to height ratio is large in the evaporating wedge, and the resulting interior deposit is most similar to the random regime that occurs at large values of equation 7 . In contrast, the sodium chloride solution (at a concentration of $36 \mathrm{~g} / \mathrm{L}, \sim 10 \%$ saturation concentration and fast crystallization kinetics) creates an outer ring that is too large, skewing the width to height ratio in the other direction and placing the final deposit in the "ring" regime of equation 7 . Of the salts tested, silver sulfate (S4f) is the closest to creating a geometry similar to that of the calcium sulfate and forms a three-dimensional ring of well-formed crystals. Thus, the drop ruptures at the interior and forms an interior ring composed of aligned crystalline needles when the contact line re-pins. However, the morphology of these crystals are different from the calcium sulfate, and the ring structures are less defined. 
To confirm the prediction of equation 7 and demonstrate that the correct geometrical ratios will give rise to patterning for salts other than calcium sulfate, we repeated the experiments with sodium chloride at other concentrations. By altering the concentration, we influence the height of outer crystal ring while maintaining a constant radius (which is set by the contact angle of the substrate). We seek a concentration that creates a three dimensional outer crystalline ring at a height sufficient to create the correct width to height ratio. The results of these experiments are shown in Figure S5, where we find that a concentric ring patterns emerges around $5 \%$ of the saturation concentration. At lower concentrations, the deposits fall into random regime due to insufficient outer height; while higher concentrions fall into the "ring" regime.
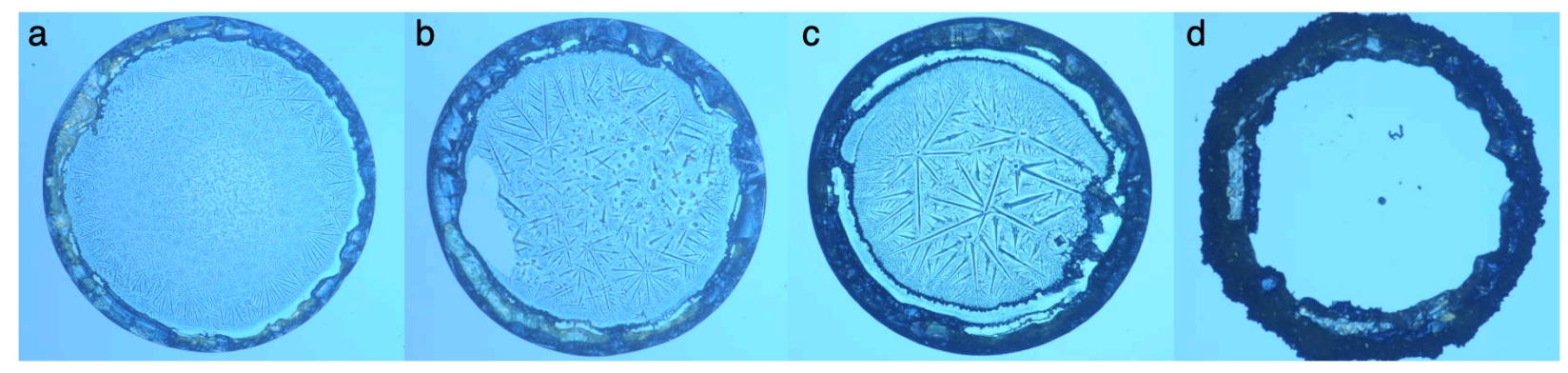

Figure S5. Depsosits from different concentrations of sodium chloride on a substrate $\left(\theta_{\mathrm{A}}=98^{\circ}\right.$, $\left.\theta_{\mathrm{R}}=30^{\circ}\right)$ heated to $70^{\circ} \mathrm{C}$. (a) $1 \%$ of saturation $(3.6 \mathrm{~g} / \mathrm{L})$, (b) $2 \%$ of saturation concentration, (c) $5 \%$ of saturation concentration, (d) $10 \%$ of saturation concentration.

While calcium sulfate is not unique in the ability to form patterns on these surfaces, it is unique in that both it's solubility concentration and it's crystallization kinetics are ideally suited for creating the three-dimensional geometry that gives rise to this patterning phenomena. It also has the added benefit of maintaining a relatively constant solubility concentration across temperatures. This property is rare, as most salts have a large increase in solubility with temperature. Thus, we were able to use temperature to vary the evaporation rate and directly compare deposits formed at different temperatures (Note: a work-around for future studies wishing to explore this effect for solutes with a temperature-dependent solubility could be to vary pressure to control evaporation rate instead).

If it is desirable to create patterns of a chemistry that does not have the unique properties of calcium sulfate, one strategy could be to use an O-ring placed on a hydrophilic substrate. A drop containing the desired solute would be placed in middle of the O-ring and allowed to evaporate. The forced geometry created by the O-ring would allow for the rupture of the drop at the interior that then allows for contact line motion patterning. Experimentalists would need to tune the height and radius of the O-ring, the evaporation rate, the solute concentration (which influences crystallization rate, crystal morphology, and -to some extent- diffusion), and the substrate wettability to fabricate the desired pattern. 


\section{Fermat's Spiral}

The spiral patterns created by drop evaporation are incomplete, in the sense that they do not begin at the origin (ie, the center of the drop). Instead, the drop ruptures, and the contact line rapidly recedes towards the exterior crystal ring for a period of time before crystallization is able to pin the contact line and commence formation of the spiral shape. For this reason, we adjust Fermat's equation so that the spiral begins at some interior radius by designating a radial dimension where the spiral begins, $\emptyset_{\text {min }}$ :

$$
r(\varnothing)=a \sqrt{\emptyset+\emptyset_{\min }}
$$

The radial dimension $\emptyset$ can be converted from radians into the number of spiral arcs, $n$ :

$$
\emptyset=2 \pi n
$$

And Fermat's equation can be rewritten as:

$$
r(n)=a \sqrt{2 \pi\left(n_{\min }+n\right)}
$$

Where $n_{\min }$ is the number of "invisible" spiral arcs, i.e, the portion of the shape that would have formed on the interior of the drop if the spiral started at the origin. The maximum radius of the spiral shapes is constrained by the inner radius of the crystalline coffee-ring, so that $r_{\text {max }}$ is a constant (which, for a constant volume, is dictated by the initial contact angle):

$$
r_{\text {max }}=a \sqrt{2 \pi\left(n_{\min }+n_{\text {obs }}\right)}=a \sqrt{2 \pi n_{\text {tot }}}
$$

Where $n_{\text {obs }}$ is the number of spirals observed, and $n_{\text {tot }}$ is the total number of spirals for a complete shape.

Figure S6 shows a selection of other spiral patterns and the fit of Fermat's equation used to generate the experimental data shown in Figure $5 \mathrm{~b}$ of the main text. 

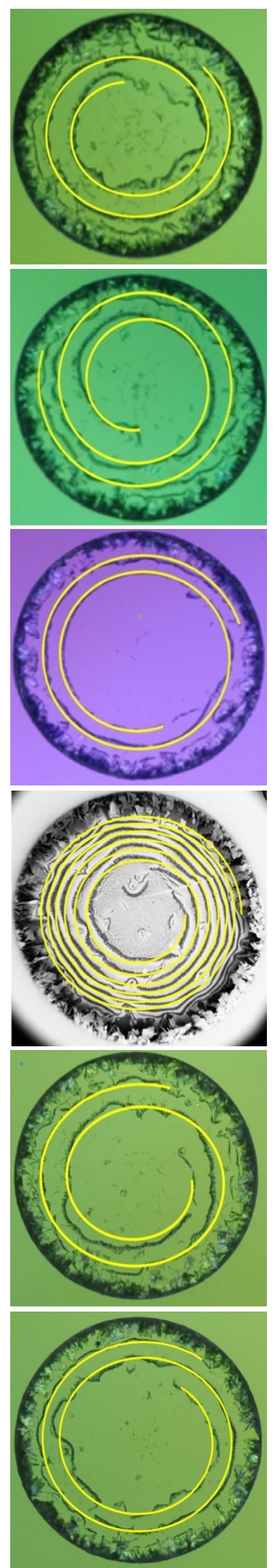

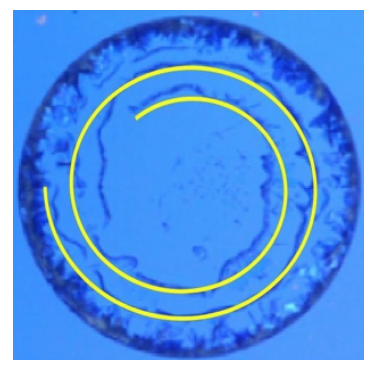

Ceria22, 70 $^{\circ} \mathrm{C}$

$r_{\text {max }}=1.18 \mathrm{~mm}$

$n_{\text {obs }}=2.3$

$n_{\text {min }}=0.5$

$n_{\text {tot }}=2.8$

$a=0.26 \mathrm{~mm}$

Ceria35, 65 $^{\circ} \mathrm{C}$

$r_{\text {max }}=1.3 \mathrm{~mm}$

$n_{\text {obs }}=1.75$

$n_{\text {min }}=1.8$

$n_{\text {tot }}=3.55$

$a=0.25 \mathrm{~mm}$

Ceria18, ${ }^{\circ} 5^{\circ} \mathrm{C}$

$r_{\text {max }}=1.17 \mathrm{~mm}$

$n_{\text {obs }}=6$

$n_{\text {min }}=1.5$

$n_{\text {tot }}=7.5$

$a=0.16 \mathrm{~mm}$

Erbia27, 65 $^{\circ} \mathrm{C}$

$r_{\text {max }}=1.18 \mathrm{~mm}$

$n_{\text {obs }}=1.8$

$n_{\text {min }}=1.3$

$n_{\text {tot }}=3.1$

$a=0.26 \mathrm{~mm}$

Erbia27, $60^{\circ} \mathrm{C}$

$r_{\text {max }}=1.17 \mathrm{~mm}$

$n_{\text {obs }}=2$

$n_{\text {min }}=3$

$n_{\text {tot }}=5$

$a=0.21 \mathrm{~mm}$

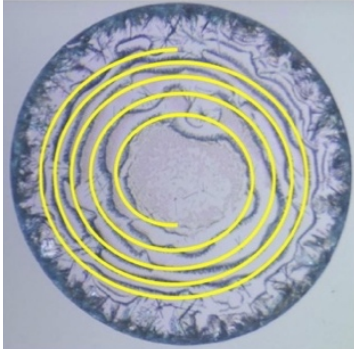

Ceria18, $6^{\circ} \mathrm{C}$

$r_{\text {max }}=1.13 \mathrm{~mm}$

$n_{\text {obs }}=4.5$

$n_{\text {min }}=1.5$

$n_{\text {tot }}=6$

$a=0.18 \mathrm{~mm}$

Ceria25, $7^{\circ} \mathrm{C}$

$r_{\text {max }}=1.20 \mathrm{~mm}$

$n_{\text {obs }}=2.6$

$n_{\text {min }}=1.65$

$n_{\text {tot }}=4.25$

$a=0.22 \mathrm{~mm}$

Ceria15, $6^{\circ} \mathrm{C}$

$r_{\text {max }}=1.12 \mathrm{~mm}$

$n_{\text {obs }}=5.1$

$n_{\text {min }}=4.7$

$n_{\text {tot }}=9.8$

$a=0.14 \mathrm{~mm}$

Ceria22, $7^{\circ} \mathrm{C}$

$r_{\text {max }}=1.17 \mathrm{~mm}$

$n_{\text {obs }}=2.5$

$n_{\min }=2$

$n_{\text {tot }}=4.5$

$a=0.22 \mathrm{~mm}$

Ceria42, $65^{\circ} \mathrm{C}$

$r_{\text {max }}=1.10 \mathrm{~mm}$

$n_{\text {obs }}=1.3$

$n_{\min }=1$

$n_{\text {tot }}=2.3$

$a=0.31 \mathrm{~mm}$

Figure S6. Optical microscope images with overlaid Fermat's spiral to measure parameter "a". 
Finally, to understand why Fermat's spiral in particular emerges from the contact line motion in these experiments, we return to the time-dependence of the radial position of the contact line. We alter Eqn S13 to indicate the time dependence:

$$
R(t)=a \sqrt{2 \pi n(t)}
$$

We track this time dependence of the radial position and plot it in Figure S7, where $n(t)$ is approximately equivalent to the radial position of the "pinning" locations.
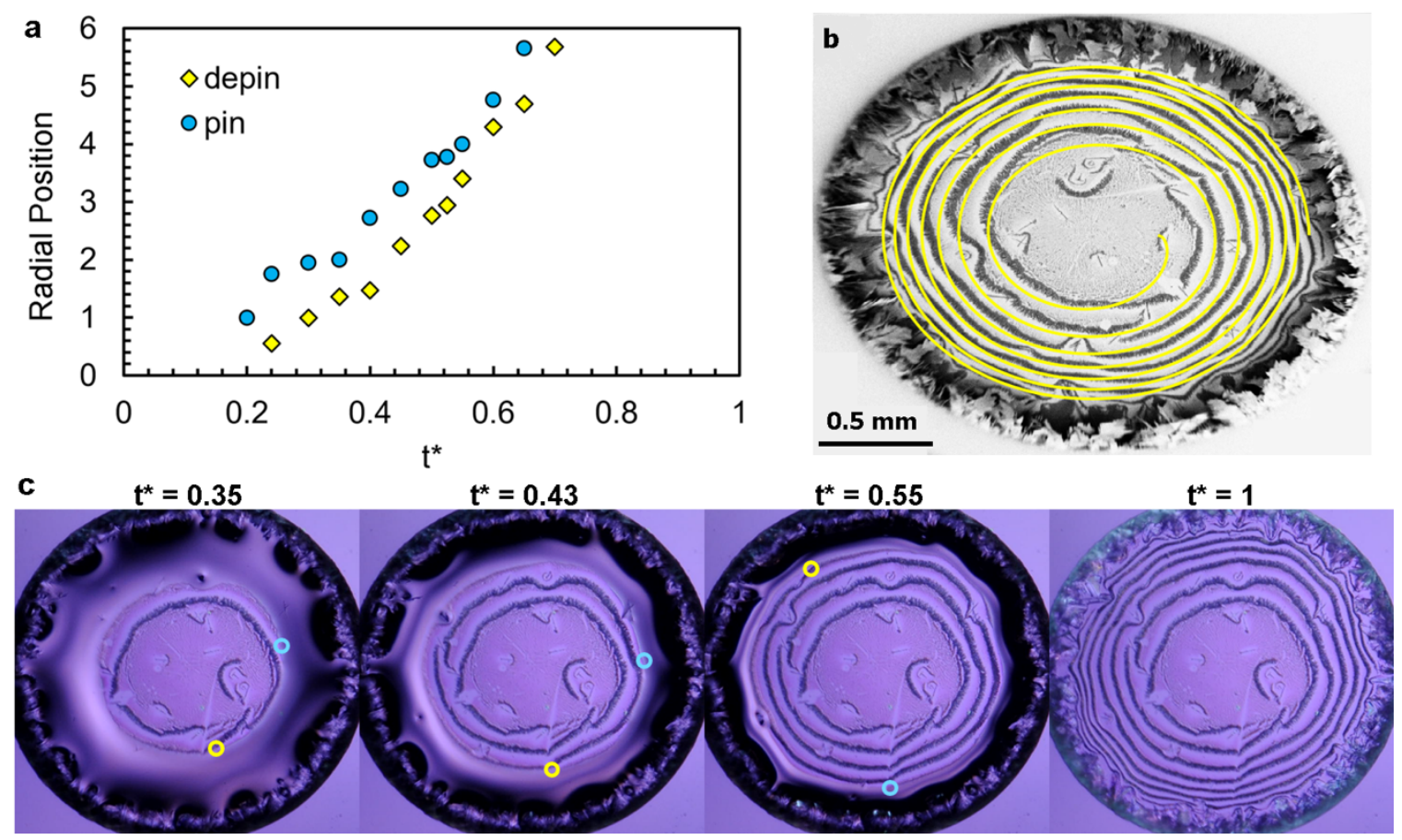

Figure S7. (a) The radial position, $n$, as a function of normalized time $\left(t^{*}=t_{1} / t_{2}\right.$, where $t_{2}$ is the burst time defined in Figure S1) (b) Fermat's equation overlaid on SEM image (same as main text Figure 5a). (c) Time series demonstrating the movement of the pinning and depinning points for the given sample.

From Figure $\mathrm{S} 7 \mathrm{a}$, we see the $\mathrm{n}(\mathrm{t})$ is approximately linear with time $\left(n(t) \sim C * t / t_{2}\right.$, where $C$ is a constant describing the slope) allowing us to specify the time-dependence of equation S15 as:

$$
R(t)=a \sqrt{\frac{2 \pi C t}{t_{2}}}
$$

We plot a normalized version of this equation, along with a normalized version of the timedependent radial position predicted from equation S9 in Figure S7 for the purposes of comparing the shapes of the two curves. 


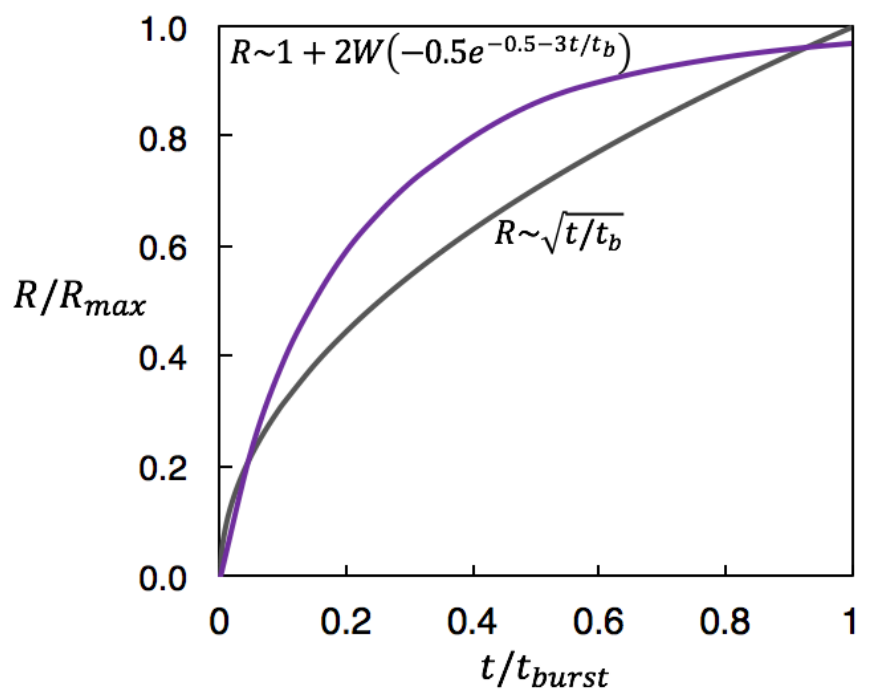

Figure S8. Plot of normalized equations S9 and S16, showing the general shape of the radial position of the contact line with time.

From Figure S8, we see that the square-root dependence predicted by Fermat's equation and the shape of the Lambert W-function predicted from a mass balance have good agreement. While not a perfect match, we are able to see how the physical model of Equation $\mathrm{S} 9$ can give rise to a shape that matches the Fermat spiral equation.

\section{Spiral vs. Concentric}

In the text, we state that spiral patterns are more likely to emerge at lower substrate receding angles. To quantify this, Table S7 gives the percent of pattern-forming (i.e., forming either concentric rings or spirals) samples that resulted in spiral patterns. Lowered substrate receding angles may be more likely to give rise to spiral shapes due to faster pinning and an associated increased likelihood of the contact line pinning in a non-uniform manner.

Table S7. Percent of pattern-forming samples that form spirals

\begin{tabular}{|c|c|c|c|c|}
\hline Surface & Color & $\boldsymbol{\theta}_{\boldsymbol{R}}$ & \#Samples & $\%$ Spiral \\
\hline Ceria12 & Purple & $12^{\circ}$ & 9 & $77 \%$ \\
\hline Ceria18 & light purple & $18^{\circ}$ & 20 & $55 \%$ \\
\hline Ceria22 & Green & $22^{\circ}$ & 11 & $64 \%$ \\
\hline Erbia27 & Green & $27^{\circ}$ & 13 & $38 \%$ \\
\hline Ceria35 & Purple/Pink & $35^{\circ}$ & 14 & $43 \%$ \\
\hline Ceria42 & Blue & $42^{\circ}$ & 15 & $23 \%$ \\
\hline
\end{tabular}




\section{Surface Characterization}

Coating Thickness. The bright colors observed on these substrates are due to differing optical properties caused by different sputter coating thicknesses. The thickness of the sputtered coatings were measured using SEM.

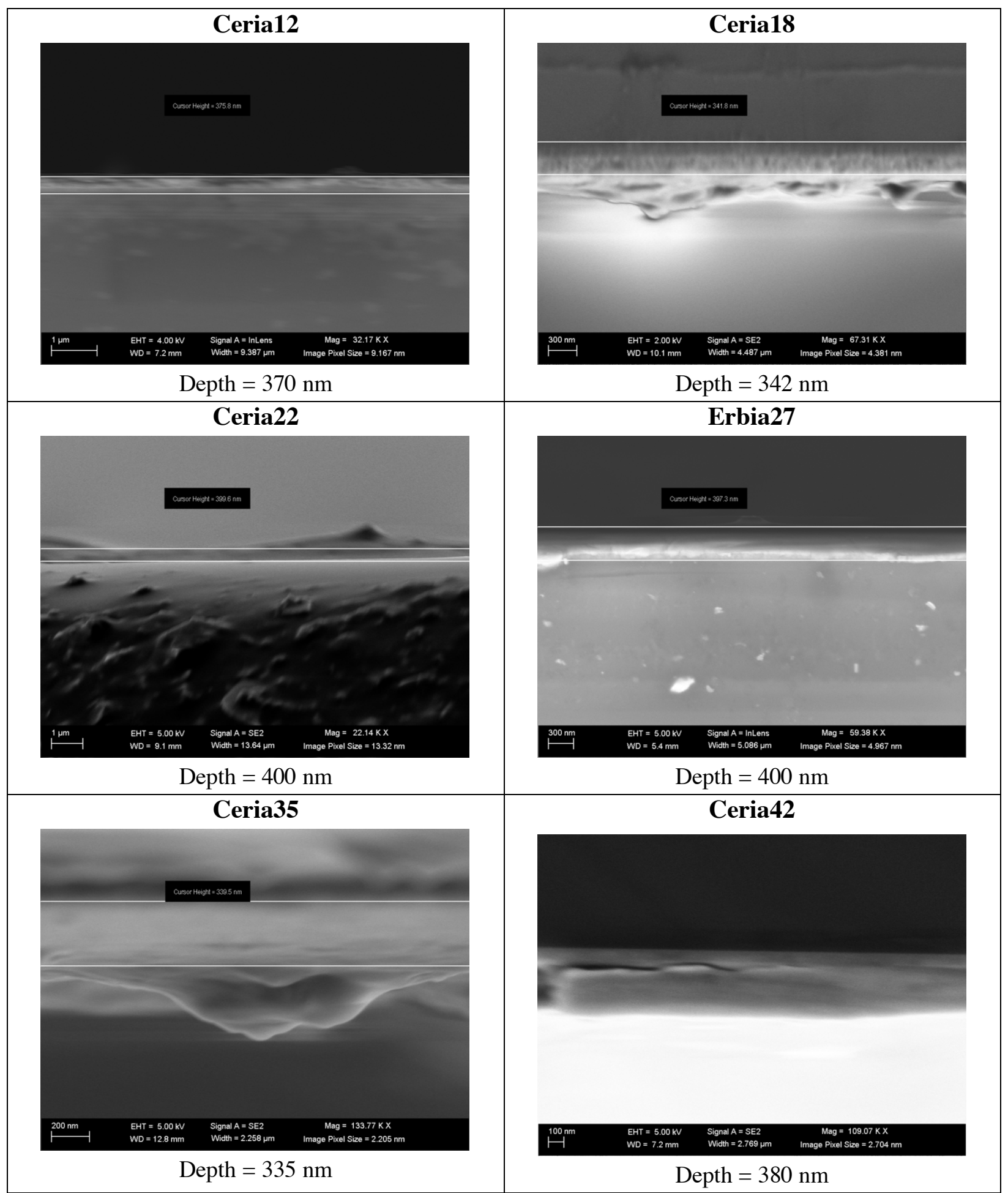


Surface Roughness. Roughness was characterized using an Asylum Research Cypher Atomic Force Microscope. Predictably, surfaces with higher surface roughness were correlated to lower receding contact angles and higher contact angle hysteresis.

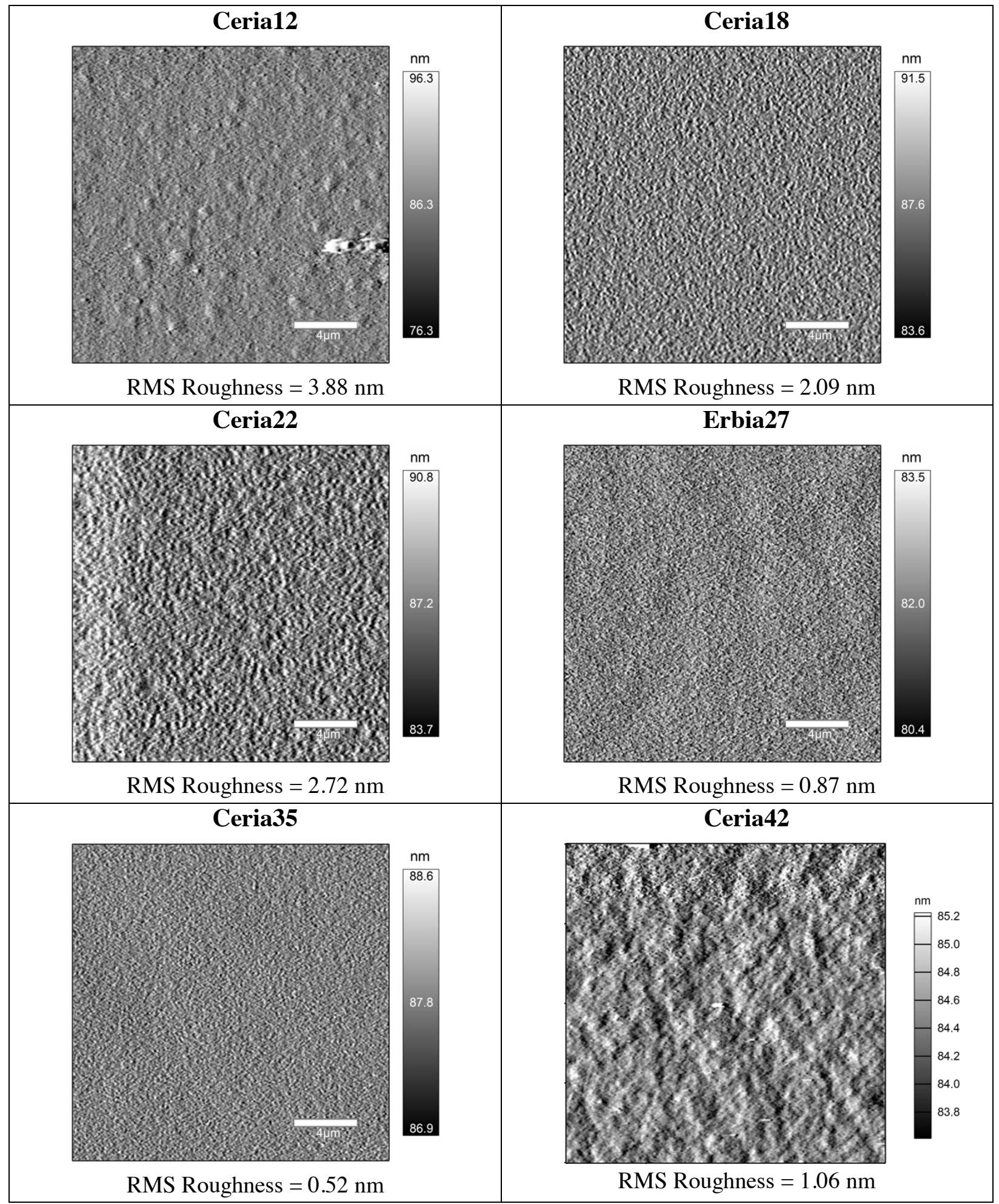


XPS. X-ray Photoelectron Spectrum measurements to characterize chemistry of the sputtered coatings were performed using a ThermoScientific K-Alpha+ XPS. The radiation used was monochromatic Al Ka with a spot size of $400 \mu \mathrm{m}$. Ten replicates of survey spectra were recorded with a pass energy of $70 \mathrm{eV}$ and an energy step of $1 \mathrm{eV}$ for a total of 1361 steps.

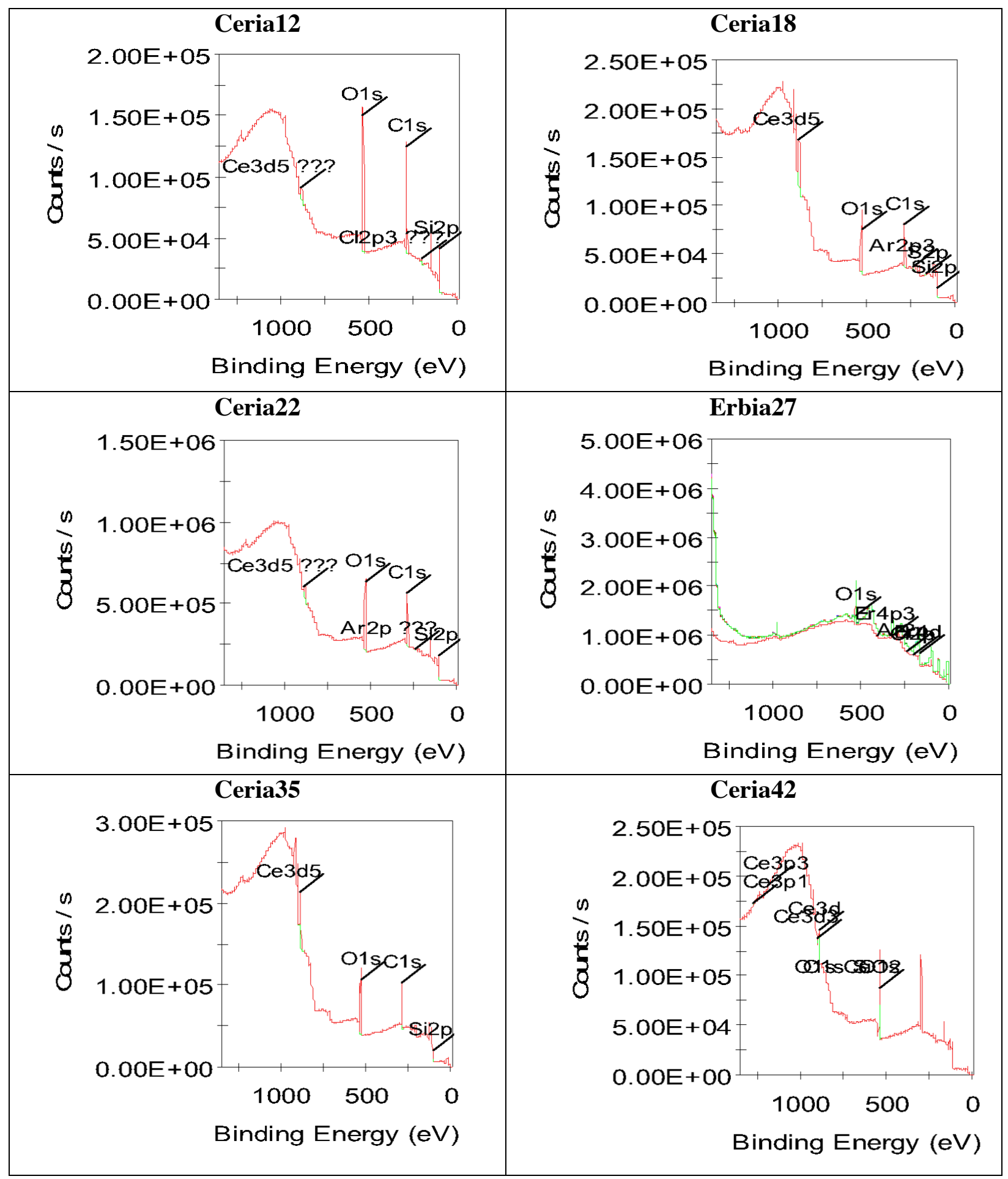




\section{Repeatability}

A number of factors influenced the repeatability of pattern formation. The first is general stochasticity associated with both drop evaporation and with crystallization. Increased roughness increased the likelihood of a non-regular pattern forming, as shown in Figure S9. In these examples of non-regular patterns, the contact line broke in unusual ways (Figure S9a,b), the surface itself was too rough and/or dirty and disrupted smooth patterns (Figure S9c), or crystals that formed in the bulk deposited on the surface and created obstacles to regular flow (Figure S9d). The problems represented in Figure S9(a,b) were a matter of luck, but the problem of S9c can be controlled by ensuring surfaces were smooth and clean, and the problem of S9d can be diminished by using freshly prepared calcium sulfate solution (ie, exactly at supersaturation and without any pre-existing seeds). While deposited crystals disrupted bulk pattern formation, SEM images reveal that spirals still form on a different length scales during droplet drying (Figure S9e). The six substrates used to generate data for this work (ie, those shown in Figure 2 of the main text and whose properties are shown in Table S1) consistently formed clean patterns.

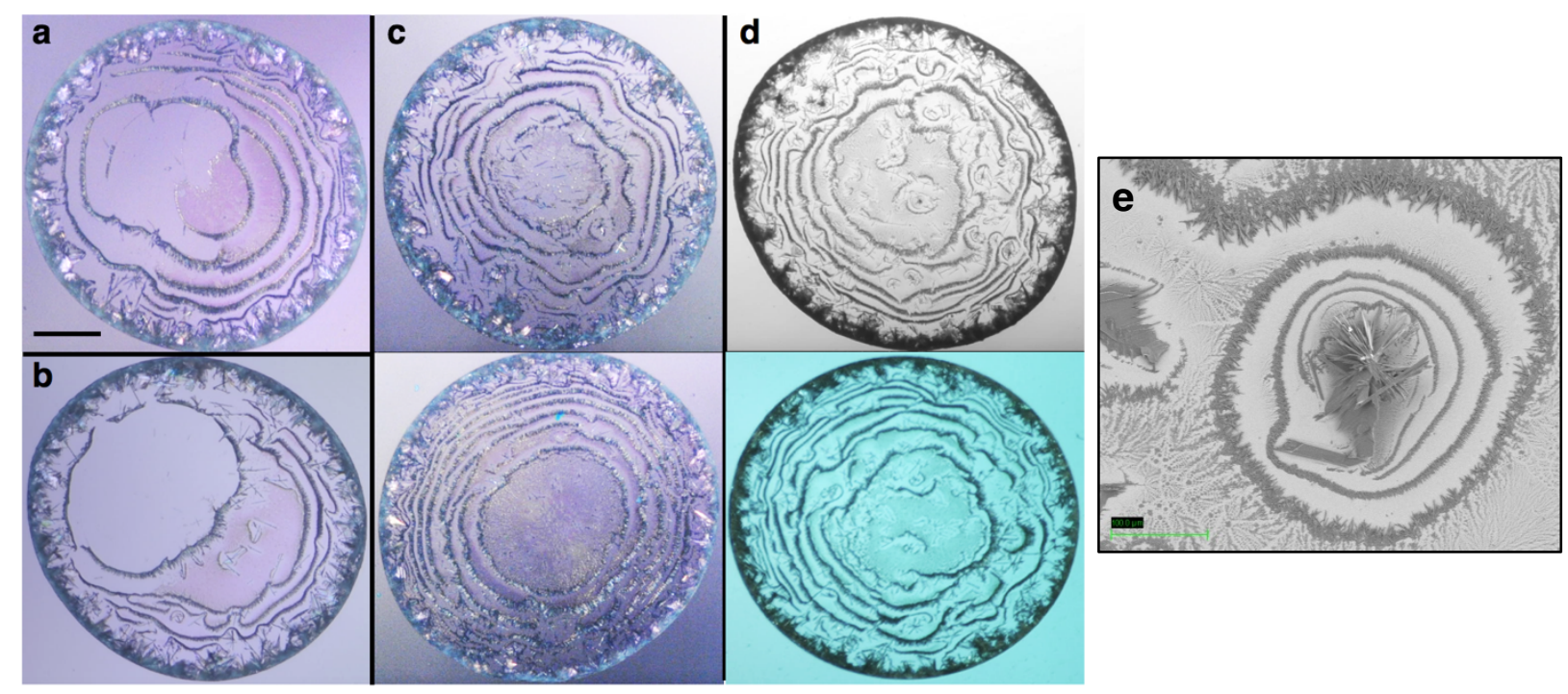

Figure S9. Some examples of samples that failed to form clean patterns. Scale bar is $0.5 \mathrm{~mm}$. (a) spirals failed to form due to crystals not pinning the contact line uniformly (b) drop ruptured on the upper left instead of at center (c) spirals failed to form due to roughness of the surface (d) calcium sulfate needles formed in the bulk deposit on the surface prior to rupture and disrupt spiral propagation. (e) Microscopic spiral has formed around a calcium sulfate crystal that formed in the bulk and deposited on the surface. 


\section{Derivation of Equation 3}

The relevant physics leading to pattern formation occur on a very small timescale in the immediate vicinity of the contact line. Thus, the timesale reported in equation S10 describing the time required for evaporation to complete after the drop has ruptured at the interior is too large to capture the relevant process. Therefore, we derive a timescale that occurs on a much smaller scale at the mobile contact line, equation 5 in the main text. Here, we show in detail how previous investigators (Poulard et al., Cachile et al., and Deegan et al.) ${ }^{6-9}$ arrive at equation 3 reported in the text.

As with the previous derivation of Equations S4-S6, we begin from the mass balance; but leave evaporative flux as a function of geometry rather than as a constant:

$$
\begin{gathered}
\frac{d m}{d t}+\nabla *(m U)=-2 \pi R \rho J(r, R, t) \\
m=\rho V_{d r o p} \\
\frac{d V}{d t}+\nabla *(V U)=-2 \pi R J(r, R, t)
\end{gathered}
$$

Throughout literature, the evaporative flux $J$ is given in different units. Here, $J$ is $\mathrm{m}^{2} / \mathrm{s}$ following Poulard/Cazabat's definition. Assuming an approximately cylindrical shape, $V=\pi R^{2} h$, and assuming that $d h / d t>d R / d t$ (valid in the case of a pinned contact line, rapid evaporation, and/or slow contact line motion), this equation becomes:

$$
\pi R^{2} \frac{d h}{d t}+\pi R^{2} \nabla *(V U)=-2 \pi R J(r, R, t)
$$

So, the height averaged mass balance equationn with a small slope is:

$$
\frac{d h}{d t}+\nabla *(h U)=-\frac{J}{R}(r, R(t), t)
$$

For a thin drop, we ignore hydrodynamic flow (see Poulard et al. 2003) ${ }^{8}$ to find:

$$
\frac{d h}{d t}=\frac{J}{R}(r, R(t), t)
$$

Where evaporative flux is the same as defined previously in equation S4; but is now given as a function of time, radial position, and contact line location: $J(r, R, t)=J_{o} * f(r, R, t) . J(r, R, t)$ was found by Deegan by analogy of an electrostatic potential, where the drop is a conductor of fixed potential with a wedge shape. ${ }^{7}$ From this analogy, he states that:

$$
\begin{gathered}
J(r) \propto(R-r)^{-\lambda} \\
\lambda=(\pi-2 \theta) /(2 \pi-2 \theta)
\end{gathered}
$$

And $\lambda \sim 1 / 2$ for low contact angles. Rather than a conducting wedge, Poulard et al. used an electrostatic analogy for a completely wetting drop as a disc rather than as a wedge. From Poulard 2005: "How to write explicitly the evaporation rate at the edge of the drop is still an open problem. This is not very serious when the contact line is pinned. The electrostatic field at the surface of a disc of radius $\mathrm{R}$ kept at a fixed potential is perpendicular to the disc surface and is written:" 9 


$$
E=-\frac{2 \Phi_{s}}{\pi} \frac{1}{\sqrt{R^{2}-r^{2}}}
$$

The evaporation rate deduced from the electrostatic analogy is:

$$
J(r, R, t)=\frac{-J_{o}}{\sqrt{1-\frac{r^{2}}{R^{2}}}}
$$

Then, mass conservation becomes (shifting the coordinates for our system where the motion moves inward-outward),

$$
\frac{d h}{d t}=\frac{J_{o}}{R(t) \sqrt{\frac{r}{R(t)^{2}}-1}}
$$

As is given by equation 3 of the main text. If we use Deegan's wedge model rather than Poulard's disc model, we find

$$
\frac{d h}{d t}=\frac{J_{o}}{R(t) \sqrt{\frac{r}{R(t)}-1}}
$$

And when we substitute in $r=R(t)+\Delta r$, we find the same scaling for either model:

$$
\frac{\Delta h}{t_{E}} \sim \frac{j_{o}}{\sqrt{\Delta r R_{\text {pin }}}}
$$

Where equation S26 is the same as equation 4 from the main text. 


\section{Additional References}

(1) Shanahan, M. E. R.; Sefiane, K. Kinetics of Triple Line Motion during Evaporation. In Contact Angle, Wettability, and Adhesion. Vol. 6; Mittal, K. L., Ed.; CRC Press, 2009; pp 19-31.

(2) Shahidzadeh, N.; Schut, M. F. L.; Desarnaud, J.; Prat, M.; Bonn, D. Salt Stains from Evaporating Droplets. Sci. Rep. 2015, 5, 10335.

(3) He, P.; Derby, B. Controlling Coffee Ring Formation during Drying of Inkjet Printed 2D Inks. Adv. Mater. Interfaces 2017, 4 (1700944), 1-6.

(4) Baldwin, K. A.; Fairhurst, D. J. Classifying Dynamic Contact Line Modes in Drying Drops. Soft Matter 2015, 11 (8), 1628-1633.

(5) Keller, J. B. Breaking of Liquid Films and Threads. Phys. Fluids 1983, 26 (7), 3451-1128.

(6) Cachile, M.; Bénichou, O.; Cazabat, A. M. Evaporating Droplets of Completely Wetting Liquids. Langmuir 2012, 18, 7985-7990.

(7) Deegan, R. D.; Bakajin, O.; Dupont, T. F.; Huber, G.; Nagel, S. R.; Witten, T. A. Capillary Flow as the Cause of Ring Stains from Dried Liquid Drops. Nature 1997, 389 (6653), 827829.

(8) Poulard, C.; Bénichou, O.; Cazabat, A. M. Freely Receding Evaporating Droplets. Final Form 2003.

(9) Poulard, C.; Guéna, G.; Cazabat, A. M. Diffusion-Driven Evaporation of Sessile Drops. $J$. Phys. Condens. Matter 2005, 17 (49), S4213-S4227. 